\title{
Produção de mudas de icozeiro (capparys yco) irrigadas com águas salinas e cobertura do substrato com fibra de coco
}

O icozeiro (Capparis yco) é uma planta endêmica do semiárido que ocorre na Caatinga do Nordeste brasileiro, desconhecida nas suas potencialidades e sua capacidade de propagação via seminal sob condições de restrições hídricas. Este trabalho objetivou avaliar os componentes de crescimento e a qualidade de mudas de icozeiro produzidas com águas salinas e uso de fibra de coco como cobertura morta. 0 experimento foi instalado em delineamento inteiramente casualizado, com quatro repetições, em arranjo fatorial $6 \times 2$, correspondente a seis níveis de condutividade elétrica da água aplicada $(0,5 ; 2,5 ; 4,5 ; 6,58,5$ e 10,5 dS m-1), no substrato sem e com cobertura morta. Foram avaliados o índice de velocidade de emergência, tempo médio de emergência, altura da planta, diâmetro caulinar área foliar, massa seca da parte aérea, massa seca da raiz, massa seca total e índice de qualidade de Dickson. A aplicação de água de alto teor salino afetou negativamente os atributos de crescimento altura das plantas, diâmetro caulinar, área foliar, massa seca da parte aérea, massa seca das raízes e massa seca total das mudas de icozeiro. A cobertura com fibra de casca de coco inibiu o crescimento e reduziu a qualidade das mudas de icozeiro. 0 uso da fibra de casca de coco como cobertura morta não é recomendado para produção de mudas de icozeiro.

\section{Production of seedlings of icozeiro (capparis yco) irrigated with saline water and substrate coverage with coconut fiber}

\begin{abstract}
The icozeiro (Capparis yco) is an endemic plant of the semiarid that occurs in the Brazilian Northeast Caatinga, unknown in its potentials and its capacity of seminal propagation under conditions of water restrictions. This work aimed to evaluate the quality of seedlings of icozeiro produced with saline water and conditions of use of coconut fiber as mulch. The experiment was installed in completely randomized design, with four replications in factorial arrangement $6 \times 2$, corresponding to the six levels of electric conductivity of irrigation water $(0.5 ; 2.5 ; 4.5 ; 6.58 .5$ and $10.5 \mathrm{dS} \mathrm{m}-1)$, the substrate without and with mulch. We evaluated the emergency speed index, average time of emergence, plant height, stem diameter, leaf area, aerial dry mass, root dry mass, total dry mass and Dickson quality index. The application of high saline water negatively affected the attributes of plant height growth, stem diameter, leaf area, shoot dry mass, root dry mass and total dry mass of the icozeiro seedlings. Coating with coconut shell fiber inhibited growth and reduced the quality of icozeiro seedlings. The use of coconut husk fiber as mulch is not recommended for the production of icozeiro seedlings.
\end{abstract}

Keywords: Agroecology; Natives species; Saline stress.

Topic: Agroecologia

Reviewed anonymously in the process of blind peer.
Received: 08/12/2018

Approved: 04/01/2019
José Lucínio de Oliveira Freire Instituto Federal da Paraíba, Brasil http://lattes.cnpq.br/9276991120133119 prof.lucinio@gmail.com

\section{Cícero Silva Dias (ii}

Instituto Federal da Paraíba, Brasil http://lattes.cnpq.br/5578960837003524 http://orcid.org/0000-0003-3832-2913

cicerosdias123@gmail.com

Jandeilson Alves de Arruda

Instituto Federal da Paraíba, Brasil

http://lattes.cnpq.br/2949292441312840

http://orcid.org/0000-0002-2775-2486

jand agro@gmail.com
Gislaine dos Santos Nascimento

Instituto Federal da Paraíba, Brasil

http://lattes.cnpq.br/6201453274367277

gislaynesantos30@gmail.com
Referencing this:

FREIRE, J. L. O.; DIAS, C. S.; ARRUDA, J. A.; NASCIMENTO, G. S.. Produção de mudas de icozeiro (capparys yco) irrigadas com águas salinas e cobertura do substrato com fibra de coco. Revista Ibero Americana de Ciências Ambientais, v.10, n.1, p.10-20, 2019. DOI: http://doi.org/10.6008/CBPC2179-6858.2019.001.0002 


\section{INTRODUÇÃO}

O bioma Caatinga tem ocorrência exclusiva no Brasil, sendo sua área principal localizada na Região Nordeste, ocorrendo também em um pequeno trecho da Região Sudeste (norte do Estado de Minas Gerais), onde predomina o clima semiárido, totalizando cerca de 734 mil km² (SILVA et al., 2003), sendo, no entanto, considerado um dos mais afetados por problemas de desertificação. Paralelo a isso, apresenta uma diversificação de espécies consideradas endêmicas com potenciais econômicos ainda pouco explorados.

Dentre as espécies nativas consideradas endêmicas dessa região, destaca-se o icozeiro (Capparis yco), que é uma planta de pequeno porte, pertencente à família Capparaceae, distribuída principalmente nas regiões tropicais e subtropicais do globo terrestre, especialmente na África e nas Américas. O gênero Capparis possui cerca de 250 espécies, sendo 15 encontradas no Brasil. 0 uso da espécie ora estudada se destaca na produção de madeira, alimentação e na medicina popular (RABÊLO, 2005).

No Estado da Paraíba, o icozeiro é encontrado em áreas esparsas das microrregiões do Seridó e do Curimataú, onde a exploração agrícola e o desmatamento desenfreado têm contribuído de forma agravante para a redução desta planta nas áreas de matas nativas. Uma das ferramentas que visam aumentar o número de acessos desta planta em habitats específicos é através da produção de mudas. Com isso, não há informações mínimas na literatura específica sobre o comportamento dela, seja com uso de água de boa qualidade ou com água com restrições quanto ao teor salino.

Para produção de mudas, ao lado do substrato de qualidade, a água é um dos principais fatores que influenciam o sucesso do empreendimento, sendo necessária uma dotação hídrica de qualidade e em quantidade. Entretanto, em muitas regiões do semiárido nordestino, há restrições quanto a água, principalmente no aspecto qualitativo, em razão de teores elevados de sais que podem comprometer a germinação, a emergência e outras fases de crescimento das plantas. Para isso, a pesquisa se debruça na busca de alternativas para reduzir os efeitos deletérios dos sais às plantas, notadamente na fase de mudas, sendo o uso de cobertura com restos vegetais uma delas.

No caso do uso de fibra de casca de coco desidratada, Rosa et al. (2002) afirma que esta é uma importante fonte de potássio, cálcio e nitrogênio, podendo influenciar positivamente no crescimento e desenvolvimento do vegetal. E este uso alternativo por, hipoteticamente, tornar o solo mais úmido e com menor temperatura na zona radicular das plantas, pode ser importante para reduzir os teores de sais neste ambiente edáfico. Com isso, esta pesquisa objetivou avaliar os componentes de crescimento e a qualidade de mudas de icozeiro produzidas com águas salinas e condições de uso de fibra de coco como cobertura do substrato.

\section{MATERIAIS E MÉTODOS}

O trabalho foi realizado entre os meses de outubro de 2017 a janeiro de 2018, em viveiro telado com cobertura plástica (filme leitoso) e cortinas laterais de tela branca com 50\% de sombreamento, no Instituto 
Federal de Educação, Ciência e Tecnologia da Paraíba, Campus Picuí, tendo como coordenadas geográficas $6^{\circ} 30^{\prime} 31^{\prime \prime}$ de latitude Sul e $36^{\circ} 21^{\prime} 49^{\prime \prime}$ de longitude Oeste, a $466 \mathrm{~m}$ de elevação.

O delineamento experimental adotado foi o inteiramente casualizado, com os tratamentos arranjados em esquema fatorial $6 \times 2$, correspondente a seis níveis de condutividade elétrica da água de irrigação $\left(0,5 ; 2,5 ; 4,5 ; 6,5 ; 8,5\right.$ e $\left.10,5 \mathrm{dS} \mathrm{m}^{-1}\right)$, no substrato com e sem cobertura morta com fibra de coco, e quatro repetições.

O substrato constou de de uma mistura de um solo Neossolo Regolítico, coletado no município de Picuí/PB, às camadas de 0 a $20 \mathrm{~cm}$, e composto à base de esterco bovino e restos de podas, na proporção 2:1. A cobertura morta constou de uma camada de $2,0 \mathrm{~cm}$ de espessura de fibra de coco (Cocos nucifera L.), seca, posta na superfície dos recipientes, cobrindo o substrato e em torno das mudas de icozeiro. Os níveis salinos das águas de irrigação foram preparados a partir da diluição de cloreto de sódio em água de baixa salinidade, com aferições de condutividades elétricas realizadas com auxílio de condutivímetro digital, modelo Stainless Hardened ${ }^{\circledR}$, conforme metodologias de Freire et al. (2015).

As mudas de icozeiro foram produzidas em recipientes de plásticos com capacidade para armazenar $3,8 \mathrm{dm}^{3}$ de solo (Figura 1A). As sementes de icozeiro foram provenientes de frutos maduros de plantas matrizes, coletados no sítio Ponta da Serra, no município de Barra de Santa Rosa/PB, sendo georreferenciadas pelas coordenadas geográficas $6^{\circ} 40^{\prime} 11^{\prime \prime}$ de latitude Sul e $36^{\circ} 6^{\prime} 34^{\prime \prime}$ de longitude Oeste, a 539 m de elevação.

A semeadura foi realizada diretamente nos vasos, sendo utilizadas duas sementes por recipiente à profundidade de $3,0 \mathrm{~cm}$. Cerca de dez dias após a estabilidade da emergência das plântulas, foi realizado o desbaste, optando-se por deixar a plântula mais vigorosa (Figura 1B). As aplicações de água nos recipientes, com alíquotas de $0,2 \mathrm{dm}^{3}$, foram efetuadas com uma frequência média de dois dias por semana.
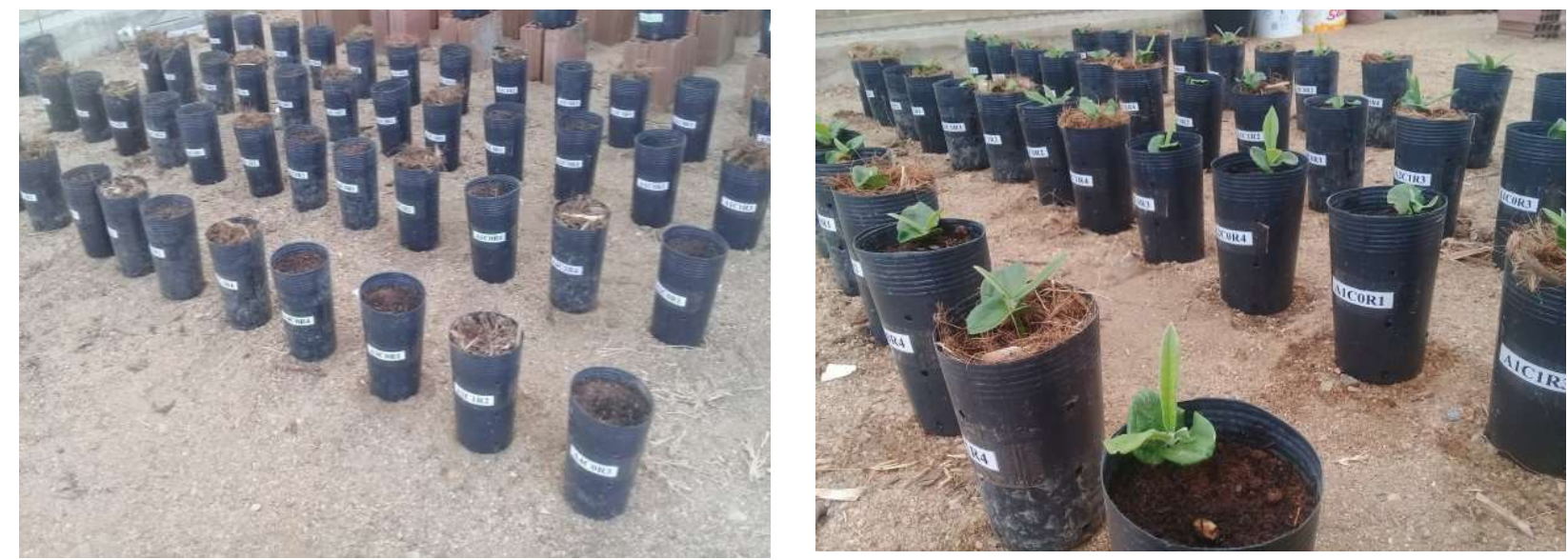

Figura 1: Disposição do experimento nos recipientes (A) e das mudas após o desbaste (B).

As variáveis analisada foram o tempo médio de emergência (TME), índice de velocidade de emergência (IVE), altura da planta $(\mathrm{cm})$, diâmetro caulinar $(\mathrm{mm})$, área foliar $\left(\mathrm{cm}^{2}\right)$, massa seca da parte aérea (g planta $\left.{ }^{-1}\right)$, massa seca da raiz (g planta $\left.{ }^{-1}\right)$, massa seca total $\left(\right.$ g planta $\left.^{-1}\right)$ e índice de qualidade de Dickson. 0 tempo médio de emergência (TME) foi calculado de acordo com Silva et al. (1995). Para o índice de velocidade 
de emergência foi utilizada metodologia de Maguire (1962), através da relação entre o número de plântulas emergidas e o número de dias que levaram para emergirem, conforme se segue:

$$
\mathrm{IVE}=\mathrm{N} 1 / \mathrm{DQ}+\mathrm{N} 2 / \mathrm{D} 2+\ldots .+\mathrm{Nn} / \mathrm{Dn}
$$

Onde: IVE = índice de velocidade de emergência; $\mathrm{N}$ = número de plântulas emergidas; $\mathrm{D}$ = número de dias após a semeadura em que foi realizada a contagem.

As alturas das plantas foram mensuradas ao final do experimento, com auxílio de régua graduada, partindo da base caulinar até o ponto de inserção das últimas folhas das plantas. Com auxílio de um paquímetro digital, modelo Stainless Hardened ${ }^{\circledR}$, foi mensurado o diâmetro caulinar. A área foliar foi estimada conforme Almeida et al. (2011), utilizando-se o comprimento do limbo foliar (C), a maior largura (L) e o fator de correção médio (FC). O fator de correção médio encontrado foi de 0,7 , verificado através do método do papel milimetrado, na qual foram desenhadas todas as folhas, de cada planta, sendo o FC determinado pela razão entre o número de quadrados milimétricos e 100 vezes o produto do comprimento do limbo foliar e a largura da folha.

$$
A F=C \times L \times F C
$$

Onde: $\mathrm{AF}=$ área foliar $\left(\mathrm{cm}^{2}\right) ; \mathrm{C}=$ comprimento foliar $(\mathrm{cm}) ; \mathrm{L}=$ largura foliar $(\mathrm{cm}) ; \mathrm{FC}=$ fator de correção. As partes vegetativas das mudas (folhas, caules e raízes) foram destacadas para determinações das fitomassas secas por meio de pesagens em balança semianalítica, após secagem em estufa de ventilação forçada, a $65{ }^{\circ} \mathrm{C}$, por 72 horas. A qualidade das mudas foi determinada pelo Índice de Qualidade de Dickson (IQD), conforme estabelecido por Dickson; Leaf e Hosner (1960):

$$
I Q D=M S T \times(A L T / D C+M S P A / M S R)^{-1}
$$

Onde:

IQD = Índice de Qualidade de Dickson; MST = massa seca total $\left(\right.$ g planta $\left.^{-1}\right)$; ALT =altura da planta $(\mathrm{cm})$; $\mathrm{DC}=$ diâmetro do caule $(\mathrm{mm})$; MSPA = massa seca da parte aérea $\left(\mathrm{g} \mathrm{planta}^{-1}\right)$ e MSR= massa seca da raiz $\left(g_{\text {planta }}^{-1}\right)$.

Os dados foram submetidos à análise de variância, processados utilizando o software estatístico SISVAR, versão $5.6^{\circ}$, com comparações de médias feitas pelo teste F ao nível de $5 \%$ de probabilidade e análise de regressão, quando os efeitos diagnósticos foram significativos (FERREIRA, 2014).

\section{RESULTADOS}

Independentemente do uso de cobertura morta com fibra de coco, a salinidade da água aplicada exerceu efeitos quadráticos na porcentagem de emergência das mudas de icozeiro (Figura 2). Nos tratamentos sem e com uso de cobertura morta e irrigação com águas salinas, as porcentagens de emergência estimadas das sementes de icozeiro foram, respectivamente, de 93,4 e $58,0 \%\left(0,5 \mathrm{dS} \mathrm{m}^{-1}\right), 82,9$ e $73,3 \%$ (2,5 dS m $\left.{ }^{-1}\right), 74,1$ e $83,4 \%\left(4,5 \mathrm{dS} \mathrm{m}^{-1}\right), 67,1$ e $88,5 \%\left(6,5 \mathrm{dS} \mathrm{m}^{-1}\right), 61,8$ e $88,4 \%\left(8,5 \mathrm{dS} \mathrm{m}^{-1}\right)$ e 58,3 e $83,1 \%\left(10,5 \mathrm{dS} \mathrm{m}^{-1}\right)$. Percebe-se que sem uso de cobertura morta, a porcentagem de emergência declina, quadraticamente, com a elevação do teor salino da água de irrigação. Com uso de cobertura com fibra de 
coco, a porcentagem máxima de emergência foi de 89,0 \%, obtida com aplicação de água de condutividade elétrica estimada de $7,5 \mathrm{dS} \mathrm{m}^{-1}$.

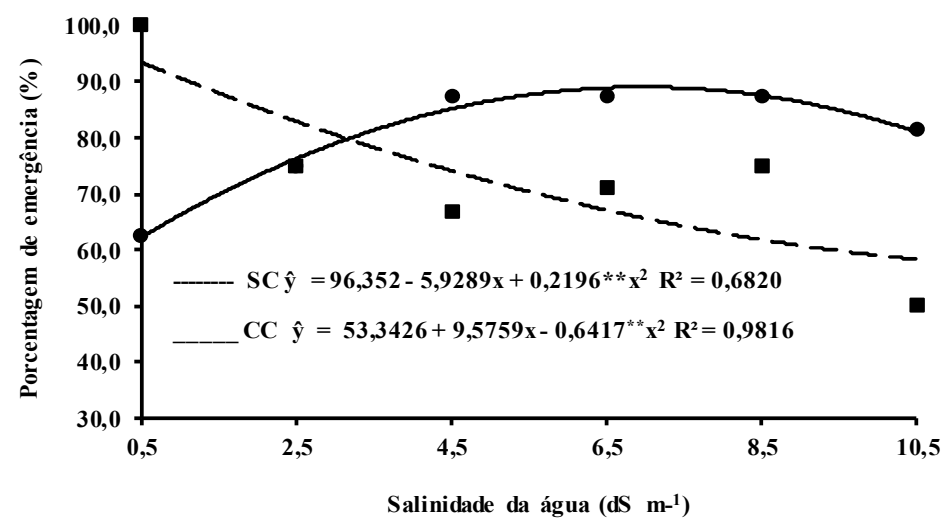

Figura 1: Porcentagem de emergência de sementes de icozeiro em substrato sem e com cobertura morta e aplicação de águas salinas.

Os fatores avaliados de salinidade hídrica e cobertura com fibra de coco, tanto os isolados, como a interação, não exerceram efeitos significativos sobre o índice de velocidade de emergência (IVE) e o tempo médio de emergência (TME), com valores médios respectivos de 0,10 e 16,0 dias. As alturas médias das mudas foram afetadas negativamente pela salinidade da água de irrigação (Figura 3), apresentando redução

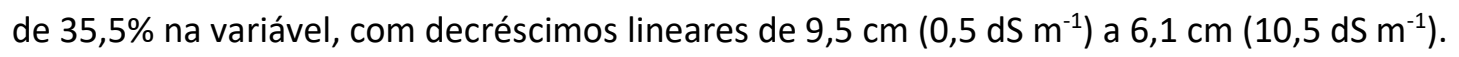

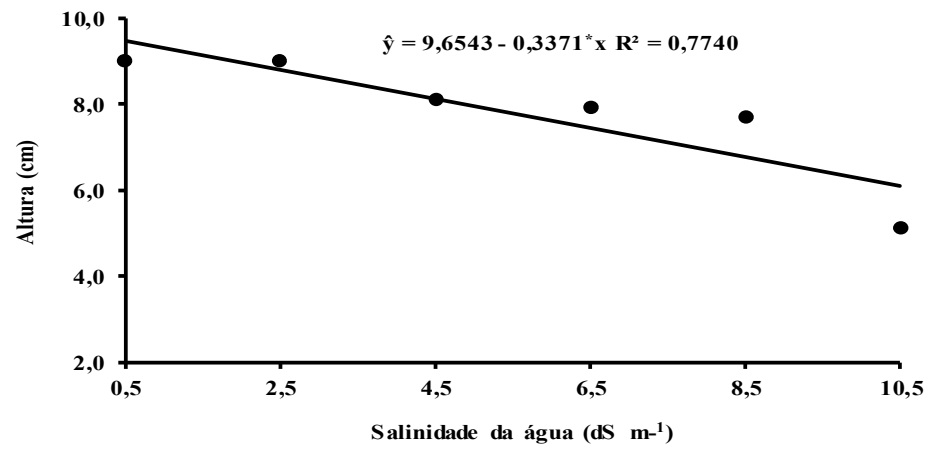

Figura 3: Alturas de mudas de icozeiro com dotação hídrica de diferentes níveis de salinidade.

Conforme observado na Figura 4, o uso da cobertura morta com fibra de coco proporcionou às mudas de icozeiro uma redução de $14,0 \%$ nos diâmetros caulinares $(3,7 \mathrm{~mm})$ quando comparado com os apresentados pelas plantas em que utilizou a fibra de coco como cobertura de substrato $(4,3 \mathrm{~mm})$.

A aplicação de água salinas e a cobertura com fibra de coco, isoladamente, exercerem efeitos significativas na área foliar das mudas de mudas de icozeiro, conforme disposto nas Figuras 5 e 6. A área foliar foi influenciada de forma quadrática pela salinidade da água de irrigação, com valores estimados de $29,8 \mathrm{~cm}^{2}\left(0,5 \mathrm{dS} \mathrm{m}^{-1}\right), 32,8 \mathrm{~cm}^{2}\left(2,5 \mathrm{dS} \mathrm{m}^{-1}\right), 32,0 \mathrm{~cm}^{2}\left(4,5 \mathrm{dS} \mathrm{m}^{-1}\right), 27,2 \mathrm{~cm}^{2}\left(6,5 \mathrm{dS} \mathrm{m}^{-1}\right), 18,7 \mathrm{~cm}^{2}\left(8,5 \mathrm{dS} \mathrm{m}^{-1}\right)$ e $6,2 \mathrm{~cm}^{2}\left(10,5 \mathrm{dS} \mathrm{m}^{-1}\right)$, com valor máximo estimado de $33,0 \mathrm{~cm}^{2}$ quando as plantas foram irrigadas com água de $3,1 \mathrm{dS} \mathrm{m}^{-1}$ (Figura 5). 


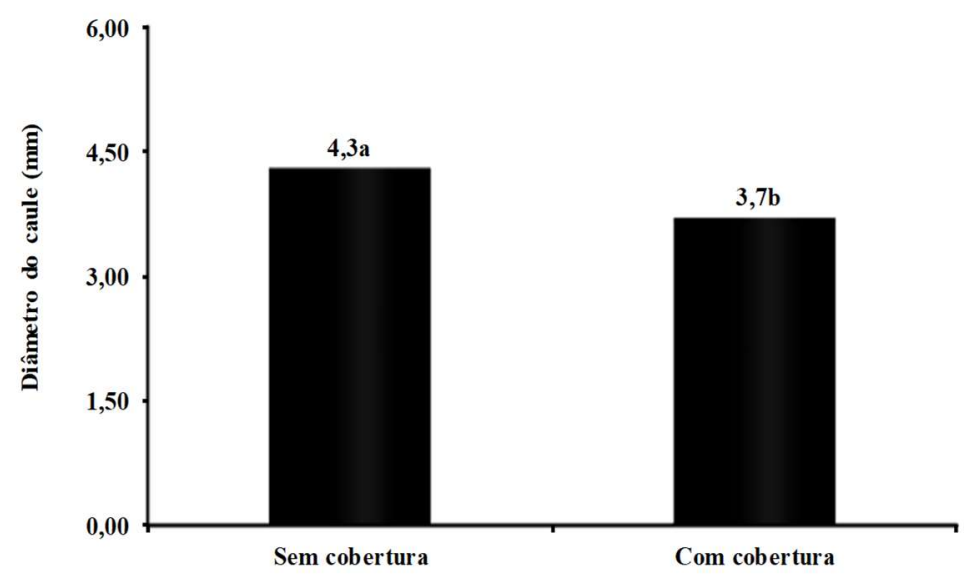

Figura 4: Diâmetro do caule de mudas do icozeiro em substrato com e sem cobertura morta.

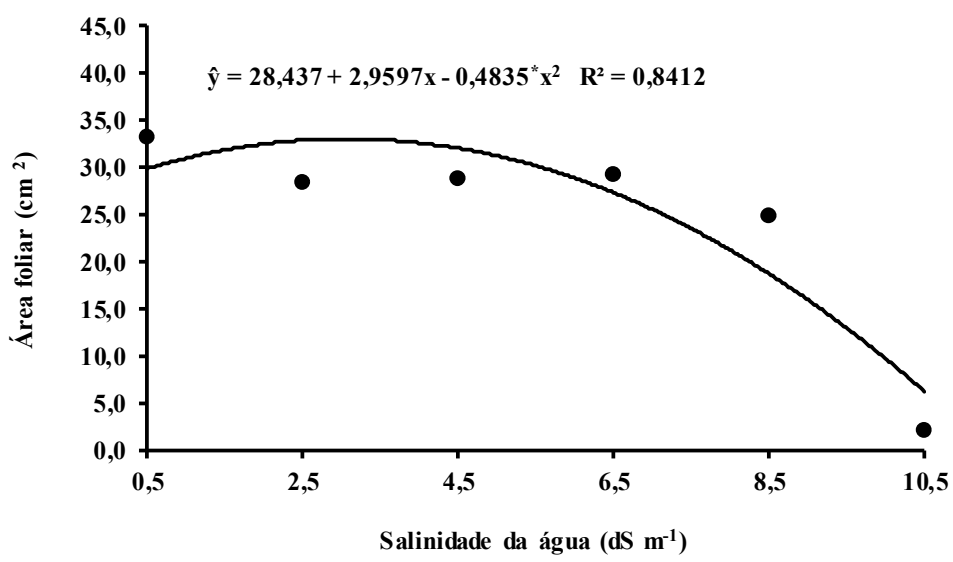

Figura 5: Área foliar de mudas de icozeiro com aplicação de águas de diferentes níveis de salinidade.

De acordo com a Figura 6, independentemente do teor salino da água aplicada, as mudas de icozeiro produzidas sem o uso da cobertura do substrato apresentaram áreas foliares superiores (73,5\%) às com o insumo orgânico como cobertura, com valores médios respectivos de 28,1 e $16,2 \mathrm{~cm}^{2}$.

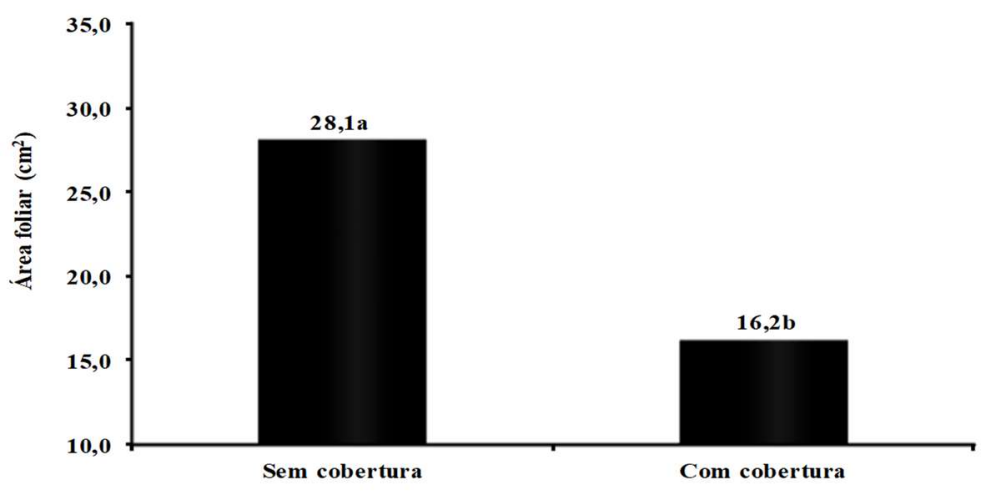

Figura 6: Área foliar de mudas do icozeiro em substrato com e sem cobertura morta.

O aumento da salinidade da água aplicada às plantas promoveu uma depleção de $67,0 \%$ na produção de fitomassa seca da parte aérea das mudas (Figura 7), apresentando valores estimados de 0,6 e 0,2 g planta1, quando a condutividade elétrica da água passou de $0,5 \mathrm{dS} \mathrm{m}^{-1}$ a $10,5 \mathrm{dS} \mathrm{m}^{-1}$, respectivamente.

A massa seca da raiz foi afetada, isoladamente, pela salinidade da água aplicadas às plantas e pela cobertura do substrato com fibra de coco (Figuras 8 e 9). A salinidade da água aplicada afetou, de forma linear, a massa seca da raiz, com redução de $0,010 \mathrm{~g} \mathrm{planta}^{-1}$ para cada aumento unitário da condutividade 
elétrica hídrica. Os teores médios de fitomassas variaram de $0,30 \mathrm{~g}^{\text {planta- }}{ }^{-1}$ a $0,20 \mathrm{~g}$ planta $^{-1}$ entre os tratamentos de menor e maior teor salino, respectivamente, conforme detalhado na Figura 8.

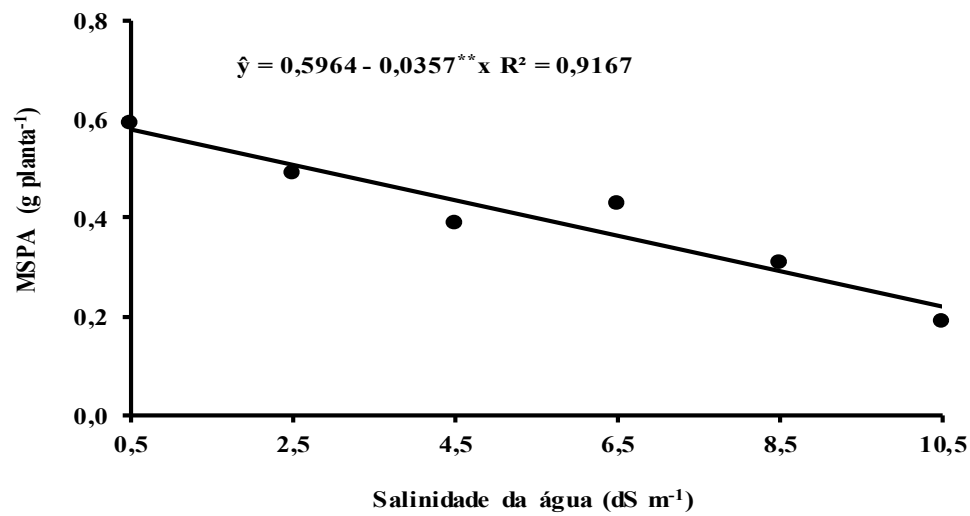

Figura 7: Massa seca da parte aérea (MSPA) de mudas de icozeiro irrigadas com águas de diferentes níveis de salinidade.

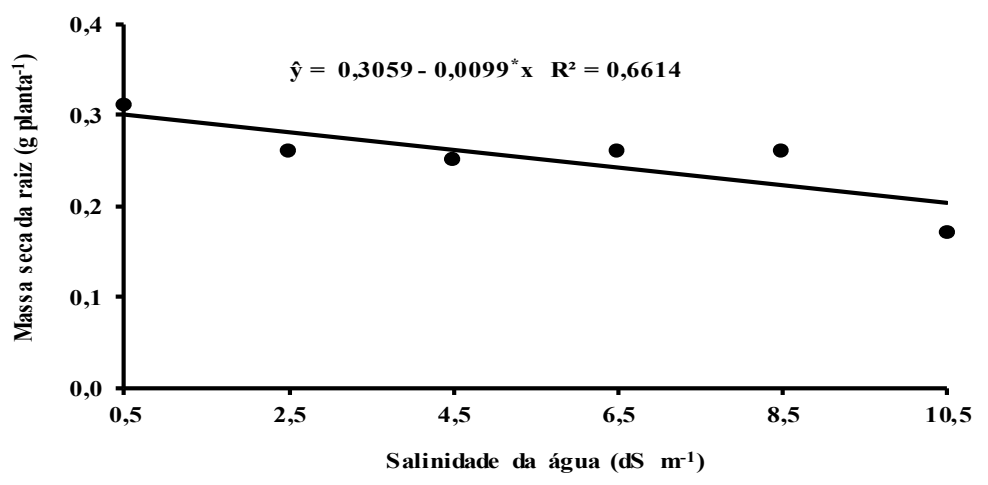

Figura 8: Massa seca da raiz de mudas de icozeiro irrigadas com águas de diferentes níveis de salinidade.

Para efeito do uso da cobertura de solo com casca de coco desidratada, verificou-se uma depleção no teor de matéria seca da raiz das mudas de icozeiros de $24,0 \%$ em relação àquelas produzidas sem o uso da cobertura, com valores respectivos de $0,29 \mathrm{~g} \mathrm{planta}^{-1}$ (sem cobertura) e 0,22 $\mathrm{g} \mathrm{planta}^{-1}$ (com cobertura), conforme Figura 9.

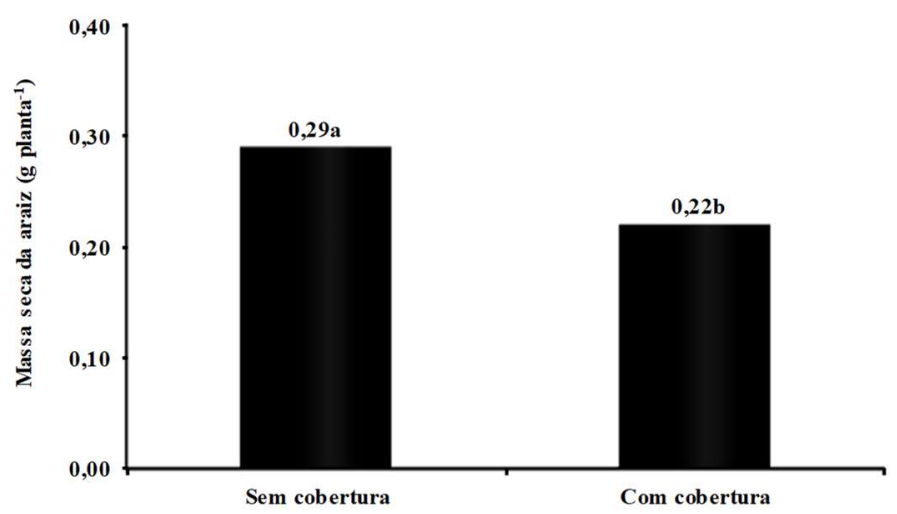

Figura 9: Massa seca da raiz de mudas de icozeiro produzidas em substratos sem e com o uso de cobertura morta.

A fitomassa seca total das mudas de icozeiro foi reduzido, de forma linear, com o aumento da condutividade elétrica das águas aplicadas. 0 decréscimo foi de $0,0601 \mathrm{~g}$ planta ${ }^{-1}$ a cada aumento unitário

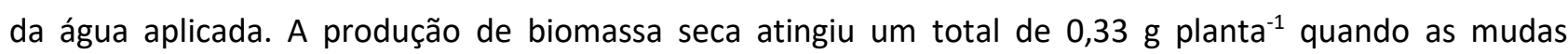
receberam tratamento com água de $10,5 \mathrm{dS} \mathrm{m}^{-1}$ e perdas de $64,5 \%$ em relação àquelas com aplicação de 
águas de $0,5 \mathrm{dS} \mathrm{m}^{-1}$ de condutividade elétrica $\left(0,93 \mathrm{~g} \mathrm{planta}^{-1}\right)$ (Figura 10). A qualidade das mudas de icozeiro foi comprometida pelo uso da cobertura do substrato com fibra de coco (Figura 11), sendo reduzida de 0,22 (sem cobertura) a 0,16 (com cobertura).

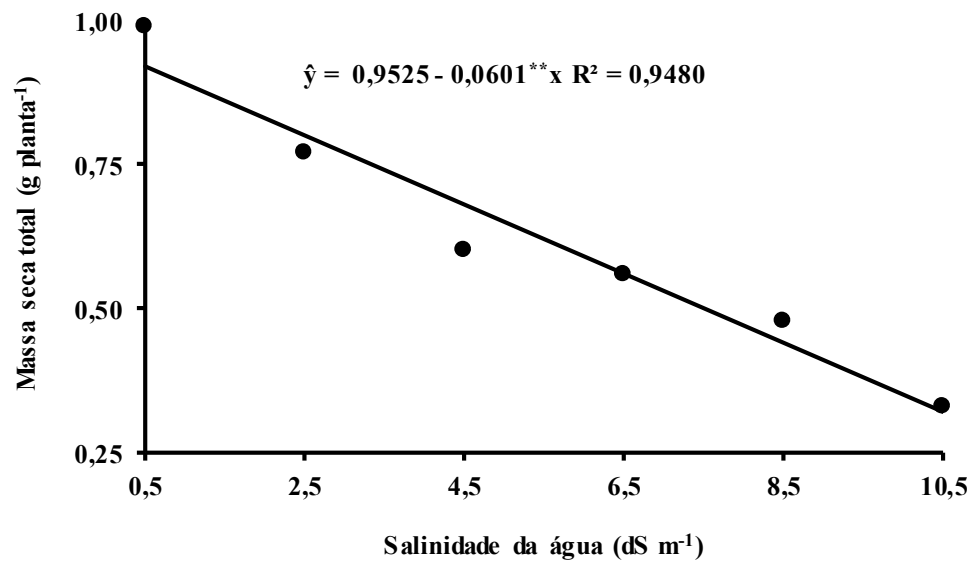

Figura 10: Massa seca total de mudas de icozeiro irrigadas com águas de diferentes níveis de salinidade.

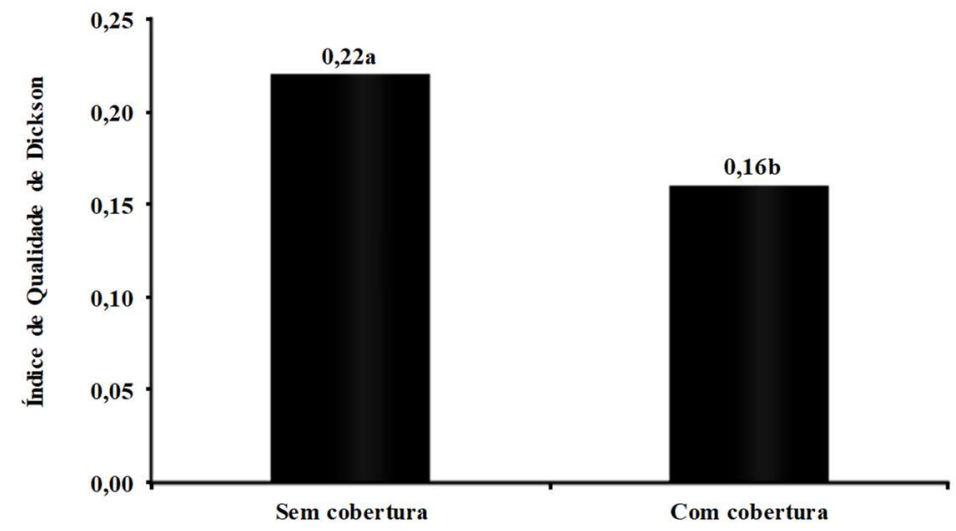

Figura 11: Índice de Qualidade de Dickson das mudas de icozeiro em substrato sem e com cobertura morta.

\section{DISCUSSÃO}

Para os resultados de porcentual de emergência de plântulas de icozeiro, dispostos na Figura 2, possivelmente, a redução do potencial osmótico do substrato, provocada pelos sais contidos na água, tenha ocasionado um impedimento físico, induzindo menor absorção hídrica, com maior concentração de sais no entorno das sementes, limitando a embebição. A menor absorção hídrica promove depleção no metabolismo vegetal, na atividade enzimática, na solubilização e transporte de fotoassimilados e, consequentemente, redução no eixo embrionário da semente, culminando com interferência negativa na germinação e na posterior emergência das plântulas (PARIDA et al., 2004; TAIZ et al., 2013), semelhante ao observado por Nicolau (2018) na produção de mudas de moringa (Moringa oleifera Lam) submetidas a estresse salino.

No que se refere ao índice de velocidade de emergência e ao tempo médio de emergência, possivelmente o icozeiro se enquadre no grupo de plantas sugerido por Gheyi et al. (2016), com respostas diferenciadas às condições de estresse salino e seja tida como mais resistente à exposição dos efeitos dos sais no decorrer do tempo necessário à emergência, independentemente dos teores salinos da água aplicada. 
O efeito deletério dos sais com inibição dos parâmetros de crescimento das mudas de icozeiro (Figura 3) encontra explicações pacíficas na literatura, pois os sais exercem efeitos osmóticos, tóxicos e nutricionais nas plantas. Entre diversos pesquisadores que confirmam esses efeitos, Farias et al. (2009) aduzem que o efeito osmótico tem sido a maior causa da redução do crescimento das plantas, associado à toxidez de íons pela absorção excessiva de $\mathrm{Na}^{+}$e $\mathrm{Cl}^{-}$e ao desequilíbrio nutricional causado pelos distúrbios na absorção e, ou, distribuição dos nutrientes. Andréo-Souza et al. (2010) afirmam que a alta concentração de sais é um fator de estresse para as plantas, limitando o crescimento de plântulas, pois reduz o potencial osmótico e proporciona a ação dos íons sobre o protoplasma. Cavalcante et al. (2010) estatuem que o excesso de sais, como sódio e cloro acarreta sérios prejuízos às propriedades físicas e químicas do solo, provocando à redução no crescimento de plantas, comprometendo as diversas etapas do crescimento vegetal, levando a situações drásticas como a morte da planta.

A redução da área foliar das mudas de icozeiro confirma as informações de Cruz et al. (2003) de que a depleção deste parâmetro de plantas cultivadas sob estresse severo de sais pode ter sido consequência da interferência negativa do tratamento salino sobre a divisão e/ou expansão celular. Essa redução na área foliar em plantas sob estresse salino, afirma os autores, é um importante mecanismo adaptativo de plantas cultivadas sob excesso de sais e estresse hídrico, visto que, sob tais condições, é interessante a redução na transpiração, com redução do carregamento de $\mathrm{Na}^{+} \mathrm{e} \mathrm{Cl}^{-}$no xilema e conservação da água nos tecidos das plantas.

Ferreira Neto et al. (2007) destacam que, quando submetidas ao estresse salino, as plantas atrasam a emissão de folhas e desativam parte de sua área foliar, na tentativa de reduzir a perda de água por transpiração, diminuindo, consequentemente, a assimilação de carbono e a produção. Para Sá et al. (2013), isso ocorre como mecanismo de defesa da planta, na qual está diretamente relacionada às trocas gasosas, notadamente ao processo de absorção de $\mathrm{CO}^{2}$ e da perda de água por transpiração, no intuito de realizar o ajustamento osmótico. Torres et al. (2014), entretanto, justificam essa redução da área foliar das plantas irrigadas com águas salinas relacionando-a ao estresse osmótico decorrente da salinidade, como forma de diminuir a perda de água pela transpiração, tendo redução na turgescência foliar provocada pelo estresse salino, na qual tem influência direta nos processos de expansão e divisão celular.

A redução na alocação de biomassa seca da parte área, raiz e total das mudas de icozeiro, corroboram com os resultados de outros autores que também observaram reduções significativas destas variáveis com uso de diferentes níveis salinos na produção de mudas de faveleira (SILVA et al., 2005) e mamoeiro (SÁ et al., 2013), classificando-a como glicófita. Nesta pesquisa, perceberam-se efeitos negativos do uso da fibra de coco como cobertura morta nos atributos de crescimento das mudas de icozeiro diâmetro caulinar (Figura 4), área foliar (Figura 6), massa seca das raízes (Figura 9), e índice de qualidade de Dickson (Figura 11).

De acordo com Carrijo et al. (2002), a casca de coco pode apresentar níveis tóxicos de tanino, de cloreto de potássio e de sódio e isso tenha contribuído para os resultados apresentados. Possivelmente, esses resultados sejam explicados em razão da produção de metabólitos secundários (aleloquímicos) oriundos da cobertura morta utilizada no experimento e que, através de interações bioquímicas, englobando alterações 
em nível celular, fito-hormonal, fotossintético e respiratório, fazendo com que haja alterações na estrutura da planta (BORELLA et al., 2011), afetando os atributos de crescimento acima elencados e a qualidade final das mudas de icozeiro. A influência da cobertura com fibra de coco na produção de mudas de icozeiro contrariou a hipótese levantada inicialmente, não mitigando os efeitos dos sais na maioria das variáveis analisadas, e nem beneficiando as mudas quando em efeitos isolados.

Para Miranda et al. (2004), a utilização da casca de coco como cobertura morta apresenta vantagens potencias, tais como reciclagem de nutrientes, redução das perdas de água por evaporação da superfície do solo e manutenção de níveis de umidade e temperatura, nas camadas superficiais do solo, adequados ao desenvolvimento de raízes e de microrganismos benéficos para as culturas. Com isso, as melhores mudas de icozeiro foram produzidas sem o uso da cobertura morta, compatível com o estabelecido por Hunt (2000), ao afirmar que para que uma muda seja considerada ideal, o IQD deve ser de no mínimo, 0,20.

\section{CONCLUSÕES}

A aplicação de água de alto teor salino afetou negativamente os atributos de crescimento altura das plantas, diâmetro caulinar, área foliar, massa seca da parte aérea, massa seca das raízes e massa seca total das mudas de icozeiro. A cobertura com fibra de casca de coco inibiu o crescimento e reduziu a qualidade das mudas de icozeiro. O uso da fibra de casca de coco não é recomendado para produção de mudas de icozeiro.

\section{REFERÊNCIAS}

ALMEIDA, J. A. R.; PEIXOTO, C. P.; PASSOS, A. R.; SANTOS, J. F.; PEIXOTO, V. A. B.. Diferentes métodos para a determinação da área foliar em genótipos de girassol. Enciclopédia Biosfera, Centro Científico Conhecer, Goiânia, v.7, n.13, p.398-403, 2011

BORELLA, J.; MARTINAZZO, E. G.; AUMONDE, T. Z.. Atividade alelopática de extratos de folhas de Schinus molle L. sobre a germinação e o crescimento inicial do rabanete. Revista Brasileira de Biociências, Porto Alegre, v.9, n.3, p.398-404, 2011.

CAVALCANTE, L. F.; CORDEIRO, J. C.; NASCIMENTO, J. A. M.; CAVALCANTE, I. H. L.; DIAS, T. J.. Fontes e níveis da salinidade da água na formação de mudas de mamoeiro cv. Sunrise Solo. Semina: Ciências Agrárias, Londrina, v.31, n.1, p.1281-1290, 2010.

CARRIJO, O. A.; LIZ, R. S.; MAKISHIMA, N.. Fibra da casca do coco verde como substrato agrícola. Horticultura Brasileira, Brasília, v.20, n.4, p.533-535, 2002.

CRUZ, J. L.; PELACANI, C. R.; SOARES NETO, W. S.; CASTRO NETO, M. T.; COELHO, E. F.; DIAS, A. T.; PAES, R. A.. Produção e partição de matéria seca e abertura estomática do limoeiro 'Cravo' submetido a estresse salino. Revista Brasileira de Fruticultura, Jaboticabal, v.25, n.3, p.524-531, 2003.
DICKSON, A.; LEAF, A. L.; HOSNER, J. F.. Quality appraisal of white spruce and white pine seedling stock in nurseries. Forest Chronicle, West Mattawa, v.36, p.10-13, 1960.

FARIAS, S. G. G.; SANTOS, D. R.; FREIRE, A. L. O.; SILVA, R. B. Estresse salino no crescimento inicial e nutrição mineral de gliricídia (Gliricidia sepium (Jacq.) Kunth ex Steud) em solução nutritiva. Revista Brasileira de Ciências do Solo, Viçosa, v.33, p.1499-1505, 2009.

FERREIRA NETO, M.; GHEYI, H. R.; FERNANDES, P. D.; HOLANDA, J. S.; BLANCO F. F.. Emissão foliar, relações iônicas e produção do coqueiro irrigado com água salina. Ciência Rural, Santa Maria, v.37, n.6, 2007.

FERREIRA, D. F.. Sisvar: a guide for its bootstrap procedures in multiple comparisons. Revista Ciência e Agrotecnologia, Lavras, v.38, n.2, p.109-112, 2014.

FREIRE, J. L. O.; CAVALCANTE, L. F.; DIAS, T. J.; DANTAS, M M. M.; MACEDO, L. P. M.; AZEVEDO, T. A.. Teores de micronutrientes no solo e no tecido foliar do maracujazeiro amarelo sob uso de atenuantes do estresse salino.

Agropecuária Técnica, Areia, v.35, n.1, p.65-81, 2015.

GHEYI, H. R.; DIAS, N. S.; LACERDA, C. F.; GOMES FILHO. Manejo da salinidade na agricultura: Estudos básicos e aplicados. In: DIAS, N. S.; BLANCO, F. F.; SOUZA, E. R.; FERREIRA, J. F. S.; NETO, O. N. S.; QUEIROZ, I. S. R.. Efeitos dos sais na planta e tolerância das culturas à salinidade. Fortaleza: INCTSal, 2016. p.151-162. 
HUNT, G. A.. Effect of styroblock design and cooper treatment on morphology of conifer seedlings. In: Target seedling symposium, meeting of the western forest nursery associations. Anais. Fort Collins: United States Departament of Agriculture. Forest Service, 2000. p.218-222.

MAGUIRE, J. D.. Speed germination and in selection and evaluation for seedlings emergence and vigor. Crop Science, Madison, v.2, p.176-177, 1962.

MIRANDA, F. R.; SOUSA, C. C. M.; CRISOSTOMO, L. A.. Utilização da casca de coco como cobertura morta no cultivo do coqueiro anão-verde. Revista Ciência Agronômica, Fortaleza, v.38, n.1, p.41-45, 2007.

PARIDA, A. K.; DAS, A. B.; MITTRA, B.. Effects of salt on growth, ion accumulation photosynthesis and leaf anatomy of the mangrove (Bruguiera parviflora). Trees Structure and Funtions, Springer, v.18, p.167-174, 2004.

RABÊLO, C. C. P.. Isolamento e caracterização parcial de lectinas em sementes de Capparis yco. Dissertação (Mestrado em Bioquímica) - Universidade Federal de Pernambuco, Recife, 2005.

ROSA, M. F.; BEZERRA, F. C.; CORREIA, D.; SANTOS, F. J. S.; ABREU, F. A. P.; FURTADO, A. A. L.; BRÍGIDO, A. K. L.; NORÕES, E. R. V.. Utilização da casca de coco como substrato agrícola. Fortaleza: Embrapa Agroindústria Tropical, 2002.

SILVA, J. M. C.; TABARELLI, M.; FONSECA, M. T.; LINS, L. V. Biodiversidade da Caatinga: áreas e ações prioritárias para a conservação. Brasília: MMA; Embrapa Semiárido, 2003.

SÁ, F. V. S.; BRITO, M. E. B.; MELO, A. S.; NETO, P. A. FERNANDES, P. D.; FERREIRA, I. B.. Produção de mudas de mamoeiro irrigadas com água salina. Revista Brasileira de Engenharia Agrícola e Ambiental, Campina Grande, v.17, n.10, p.1047-1054, 2013.

SILVA, M. B. R.; BATISTA, R. C.; LIMA, V. L. A.; BARBOSA, E. M.; BARBOSA, M. F. N.. Crescimento de plantas jovens da espécie florestal favela (Cnidosculus phyllacanthus Pax \& K. Hoffm) em diferentes níveis de salinidade da água. Revista de Biologia Ciências da Terra, São Cristóvão, v.5, n.2, 2005.

SILVA, J. B. C.; NAKAGAWA, J.. Estudo de fórmulas para cálculo da velocidade de germinação. Informativo ABRATES, Londrina, v.5, n.1, p.62-73. 1995.

TORRES, E. C. de M.; FREIRE, J. L. O.; OLIVEIRA, J. L.; BANDEIRA, L. B.; MELO, D. A.; SILVA, A. L.. Biometria de mudas de cajueiro anão irrigadas com águas salinas e uso de atenuadores do estresse salino. Revista Nativa, Sinop, v.2, n.2, p.71-78, 2014

A CBPC - Companhia Brasileira de Produção Científica (CNPJ: 11.221.422/0001-03) detém os direitos materiais desta publicação. Os direitos referem-se à publicação do trabalho em qualquer parte do mundo, incluindo os direitos às renovações, expansões e disseminações da contribuição, bem como outros direitos subsidiários. Todos os trabalhos publicados eletronicamente poderão posteriormente ser publicados em coletâneas impressas sob coordenação da Sustenere Publishing, da Companhia Brasileira de Produção Científica e seus parceiros autorizados. Os (as) autores (as) preservam os direitos autorais, mas não têm permissão para a publicação da contribuição em outro meio, impresso ou digital, em português ou em tradução. 